\title{
E-payments: Go digital, go cashless
}

\author{
Jaideep Inder Kaur \\ Assistant Professor, Kamla Nehru College for Women,Phagwara.
}

\begin{abstract}
Today's India is now completely different from earlier India. Now a day's India become cashless due to biggest decision ever taken of demonetization. Demonetization is a process in which.Cashless India is famous in current days which makes easier people's life. People can easily do e-payments everywhere 24*7. People don't need cash in their hands even Indian government also promote e-payments infrastructure. There is no need to carry even credit cards or debit cards when you have e-wallet. Government promotes UPI (Unified Payment Interface) and Paytm (pay through mobile) online applications with this every transaction are linked with your account and you can proceed to pay anywhere for shopping, paying bills and any online transaction over there. In this research paper light is thrown on these two folds: UPI and Paytm. How they works, their benefits and weaknesses and which one is more beneficial to use.
\end{abstract}

Keyword: Overview, how they works, Benefits and weakness.

\section{Overview}

From past few years global payments are increasing day by day. Life is so fast that we always want to do everything fastly. Over the past 10years, smart phones seem to give us more power to perform whatever we want to do within seconds. People can't afford to waste their time and can't wait to perform their work manually. They need now one touch solution for everything whether it is for shopping, paying bills, online transactions etc. and all is now happening through the digital payments. The last two to three months heightened this to perform on a large scale because of demonetization. Everyone is facing problem of cash and our society becomes cashless society. But now with two helping payment systems that is UPI (Unified Payment Interface) which is launched by NPCI (National Payment Corporation of India) under guidance of RBI (Reserve Bank of India) and Pay tm( pay through mobile) launched by Fin tech in India and owned by one 97 communications solve our problems of cash and helps to become a cashless society but with cash in their pockets.

\section{UPI (Unified Payment Interface)}

UPI is launched by NPCI which also launched IMPS(Immediate Payment system) online payment system.UPI is one step ahead to IMPS and it make society completely cashless and digital. UPI helps to perform our e-payments vastly through our smart phones. It is promoted by our government in these days on large scale especially by our PM Narendra Modi ji. He wants our society to be completely digital with the help of UPI system. It helps us to perform our transaction $24 * 7$ from our accounts and avail the benefits of net banking. It helps to eliminate the use of multiple entries of our debit card or credit card details to perform transactions on the sites through which phishing and hacking is possible.

\section{Paytm (Pay Through Mobile)}

Paytm is a mobile app which is widely used and accepted by customers for their important cores like paying bills, fees, ticket bookings, mobile and dish recharges and shopping anytime anywhere $24 * 7$. Paytm is India's largest e-payment platform. This app is launched in 2010 by Fintech Company and it is owned by one 97 communications. It makes our life so much easy by just have one touch and all cores are done. And now with the help of Modi ji whole market is digital. Going to market for buying anything, and payment for that now just a matter of seconds as Paytm is installed everywhere just go and pay by scanning their code. No need to carry cash now and promoting to be advanced society with no cash and still buy everything by being digital. 
UPI:

\section{How These Applications Works}

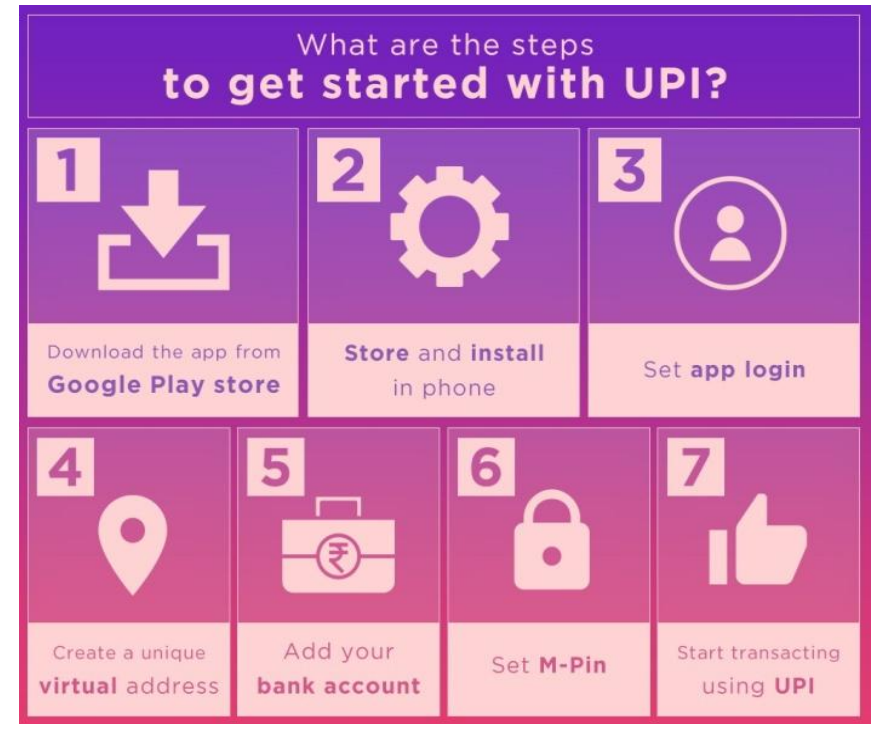

- To use this application person needs smart phone on which UPI app is installed and person bank account.

- After having app user needs to get registered on app with UPI ID and his/her bank details.

- UPI ID is a unique virtual id just like an email id.

- User then set their unique pin to perform transactions through this app i.e. funds transfer from account to any other account and even receive payments from any other account.

- User can perform payments by using virtual id number, adhaar card number, account number and mobile number.

- Those who don't have smart phone and UPI app that user just need to dial *99\# to perform payments, rest process is same by getting id, payments can be done.

\section{Paytm:}

- To perform transactions on this app user just needs smart phone. Then user can download and installed Paytm application from Google play store.

- Then user creates a user id and password to login in this app.

\section{Working and technology of Paytm}

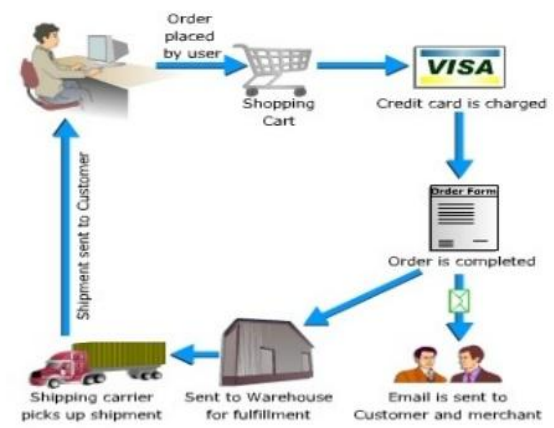

\section{paytim}

- Then we can add money from our debit card to this just like having e-wallet. We can perform any kind of payment through this application i.e. ticket booking, paying bills, recharges and even now we can pay money through our e-wallet to any person by just scanning their code on any shop. We can even receive money through this application. It is quite easy to use and makes our life easier too. 


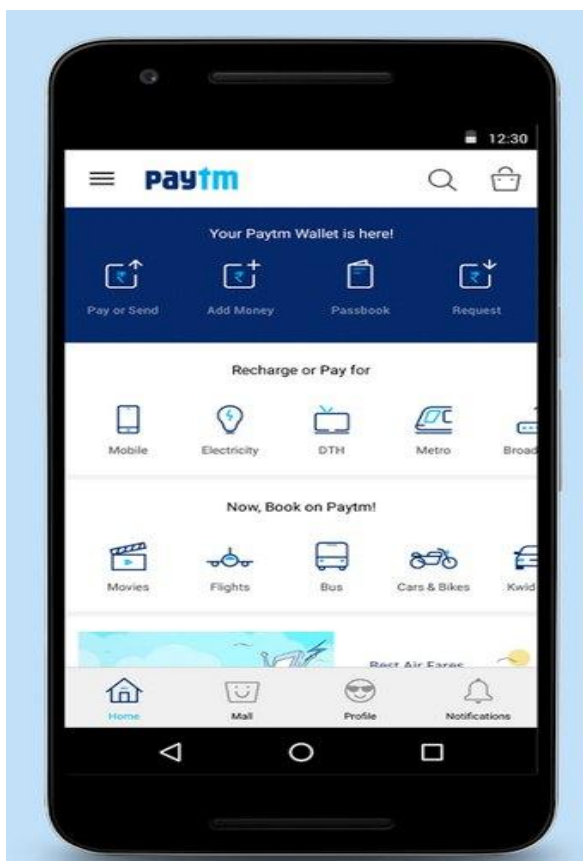

\section{Benefits And Weakness}

\section{Benefits of UPI application:}

- UPI is safe and tested under guidance of RBI (Reserve Bank of India).

- UPI makes payments possible done by just one click.

- UPI doesn't need to shift money from bank account to any other app login account so money is always safe and secure.

- UPI is interoperable.

- UPI is one extension of IMPS architecture which provides the services $24 * 7$ in an easy and manageable way.

- UPI reduces the risk of getting details leaked or hacked by using multiple times i.e. your account number, card number, one time passwords, phone number, bank name, IFSC number, or bank branch.

- UPI can also be used to send requests for money just like invoices.

- Customers can use same virtual id to make any kind of payments by payer as well as payee to receive payments through the same id.

- Customer can avail all benefits of banking services.

Paytm:

- It is most widely \& easiest used applications for e-payments.

- It saves user time for performing variety of cores in just one simple click.

- Paytm also helps a lot us to carry e-wallet not physical wallet which makes us tension free from losing our wallet somewhere or worried about cash. Just go anywhere cashless and enjoy being digital.

- Very rare chances of unsuccessful transactions. It provides reliable services to get always successful transactions in return.

- Paytm provides smooth and easy payment scenario. Anyone can easily understand how to make transactions through this application.

- It also works for $24 * 7$ days.

- It provides variety of profits like cash back, free coupons and discounts on various deals.

\section{Weakness:}

- The biggest disadvantage of applications or being digital and cashless is if internet is not working we become helpless and again cashless. We are not able to perform anything as we will not able to buy anything.

- As well as user have big issue of security these applications are secure enough but we don't have enough much guarantee that our personal data is not hacked or used by someone else. 
- It does not fulfill requirements of all society because many persons are illiterate in this country and to make them literate for these applications takes so much time.

- It covers many of our solution to go cashless and support demonetization but still there are many places in which we neither have Paytm nor have card system like travelling in bus we can't buy ticket through Paytm and even it is not possible to always travel through bus on which ticket is already booked.

\section{Why To Choose Upi Over Paytm}

Even our government promotes UPI for being digital and go cashless but still they installed Paytm in every shop, restaurants and many such places where we can't swipe our cards for our ease so that users do not suffered as they are already suffering in bank lines or ATM lines for cash.

- UPI is already tested and verified as it is already has same architecture like IMPS under guidance of NPCI(National Payment Corporation of India) and RBI (Reserve Bank of India).

- UPI is good for fund transfer from or to any account and for that every user should have adhaar card number, bank account number, IFSC number and many more details.

- UPI is able to exchange information easily and makes best use of it. It is operable whereas e-wallets are not.

- UPI provides maximum amount to transfer through id is one lakh whereas Paytm or any other e-wallets just provide only 10,000/-cash to spend or transfer.

- UPI is safe process as money doesn't need to transfer again and again whereas in Paytm is not safe to shift money and always giving personal details to any application over internet. Money stays safe in their account.

- But for making payments through Paytm user just need a Paytm in his/her phone and e-money in their ewallet. Then just scan their bar code and payment is done within seconds. It is easier but not safe always.

- So both applications have their own advantages for funds transfer UPI is best but it will take time to make people aware about this application till that time period for some places and some transactions should be operated by Paytm like for bill payments, shopping, recharges, ticket booking. For long run if it works properly UPI achieve big fan following and makes our life much easier than before.

\section{Conclusion}

At the end I sum up my views that somewhere demonetization is bliss for Indian society if it works properly. Demonetization helps to become our society digital and cashless. With the help of this tiny effect is seen on corruption and even black money is also come out. This process will take time to get clean India from those impurities like black money, corruption and many more. These two applications improve a lot and help a lot to be digital and cashless. With the more use of these applications Indians promotes Modi ji slogan go digital, go cashless India. These applications ease our life and provide everything in our hand with just one single touch and offers facility to go anywhere without worry of cash. There is no need to carry wallet.

\section{References}

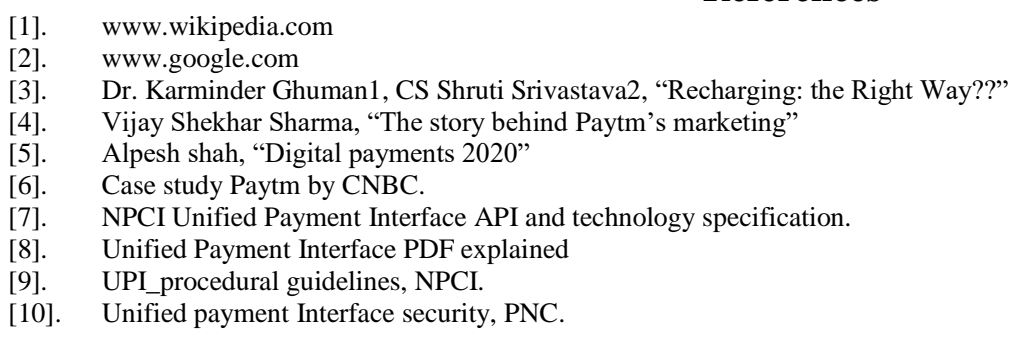

